\title{
TEKNIK PENANGKAPAN IKAN TILAN (Mastacembelus spp.) MEMAKAI ALAT TANGKAP TAJUR RENDAM (FISHING LINE) DI SUNGAI MUSI BAGIAN HILIR, SUMATERA SELATAN
}

\author{
Burnawi ${ }^{11}$ \\ 1)Teknisi Litkayasa pada Balai Riset Perikanan Perairan Umum, Mariana-Palembang \\ Teregristasi I tanggal: 15 Agustus 2006; Diterima setelah perbaikan tanggal: 25 Agustus 2006; \\ Disetujui terbit tanggal: 23 Maret 2007
}

\section{PENDAHULUAN}

Sungai Musi merupakan sungai terpanjang di Sumatera Selatan yang memiliki 2 anak sungai yang terbesar yaitu Sungai Komering, Sungai Ogan (Gaffar, 1997). Karakteristik Limnologi Sungai Musi dibagi menjadi 3 wilayah yaitu wilayah hulu, tengah, dan hilir (Samuel et al., 2002). Sungai Musi bagian hilir sungai yang besar dan dalam dipengaruhi pasang surut air laut dan terdapat jenis ikan ekonomis penting seperti ikan tilan (Mastacembelus spp.), patin (Pangasius spp.), udang galah (Macrobrachium rosenbergii), betutu (Oxyleotris marmorata), baung (Mystus nemurus), dan lampam (Barbodes schwanenfeldii).

Ikan tilan di Indonesia ada 5 jenis yaitu $M$. erythrotaenia, M. keithi, M. maculatus, $M$. notopthalnus, dan M. unicolor. Daerah penyebaran ada di Pulau Sumatera, Kalimantan, dan Jawa (Kottelat et al., 1993). Ikan tilan termasuk kelompok ikan karnivora yang suka makan udang dan siput, hidup dan berkembang biak di sungai-sungai besar dan sungai kecil di bagian hulu sampai dengan ketinggian $\pm 900 \mathrm{~m}$ dari permukaan laut. Ikan tilan merupakan ikan konsumsi dan hias yang diekspor ke manca negara dan harga ikan tilan ditingkat nelayan berkisar Rp.10.000,- sampai dengan 15.000 per kg.

Kegiatan perikanan di Sungai Musi yang dominan adalah penangkapan ikan. Beberapa alat tangkap yang digunakan oleh nelayan adalah tajur rendam, pancing, rawai, jala, jaring insang, bubu, tuguk, dan belat. Sedangkan alat tangkap yang sering digunakan untuk menangkap ikan tilan ada 2 macam yaitu tajur rendam dan belat. Tajur rendam digunakan pada musim penghujan yaitu bulan Desember sampai dengan Januari dan alat tangkap belat dilakukan di musim kemarau yaitu bulan Mei sampai dengan September.

Tujuan dari makalah adalah memberikan informasi pembuatan dan operasional alat tangkap tajur rendam di Sungai Musi bagian hilir, Sumatera Selatan.

\section{BAHAN DAN METODE}

\section{Spesifikasi Perahu Motor}

Spesifikasi perahu motor antara lain bahan berupa kayu meranti panjang $3 \mathrm{~m}$, lebar 80 sampai dengan $100 \mathrm{~cm}$, tinggi $50 \mathrm{~cm}$, mesin $3 \mathrm{PK}$.

\section{Spesifikasi Alat Tangkap Tajur Rendam (Fishing Line)}

Spesifikasi alat tangkap tajur rendam (fishing line) antara lain tali nylon No.80, pancing No.12, batang (stick) bambu ukuran panjang $3 \mathrm{~m}, \varnothing 1$ sampai dengan $1,5 \mathrm{~cm}$, dan alat tangkap bersifat statis.

\section{Cara Membuat Tajur Rendam}

Cara membuat tajur rendam sebagai berikut:

1. Diambil beberapa batang bambu dipilih yang telah tua, relatif lurus, dan ranting-ranting dibersihkan menggunakan pisau, kemudian dipotong sepanjang $3 \mathrm{~m}$.

2. Tali nylon dipotong sepanjang $120 \mathrm{~cm}$ menggunakan gunting salah satu ujung di dipasang pancing dengan cara simpul mati agar kuat.

3. Tali nylon yang diberi pancing diikatkan di tengah bambu \pm dengan jarak $100 \mathrm{~cm}$ dari batang bambu pada bagian bawah (Gambar 1).

\section{Cara Pengoperasian Alat Tangkap Tajur Rendam}

1. Semua bahan dan peralatan dimasukkan ke dalam perahu motor untuk diangkut ke tempat penangkapan yang telah ditentukan.

2. Sebelum dioperasikan alat tangkap tajur rendam diberi umpan udang segar dengan cara dikaitkan pada pancing sampai dengan cukup kuat, umpan udang dengan ukuran panjang rata-rata $3 \mathrm{~cm}$ dan bobot rata-rata $4 \mathrm{~g}$.

3. Kebutuhan udang untuk umpan setiap kali operasional penangkapan diperlukan $\pm 1 \mathrm{~kg}$ per 300 sampai dengan 400 buah tajur rendam.

4. Tajur rendam dioperasikan selama \pm 2 jam pada saat air pasang tertinggi, dipasang dengan jarak 2 sampai dengan $5 \mathrm{~m}$ mengikuti alur sungai dari hilir ke hulu atau sebaliknya, dipasang dengan jarak 0 sampai dengan $1,5 \mathrm{~m}$ dari pinggiran sungai atau melihat kondisi tinggi air pasang pada saat itu dan dipasang secara tegak yang ditancapkan didasar sungai sampai dengan kedalaman $\pm 20 \mathrm{~cm}$. (Gambar 2). 


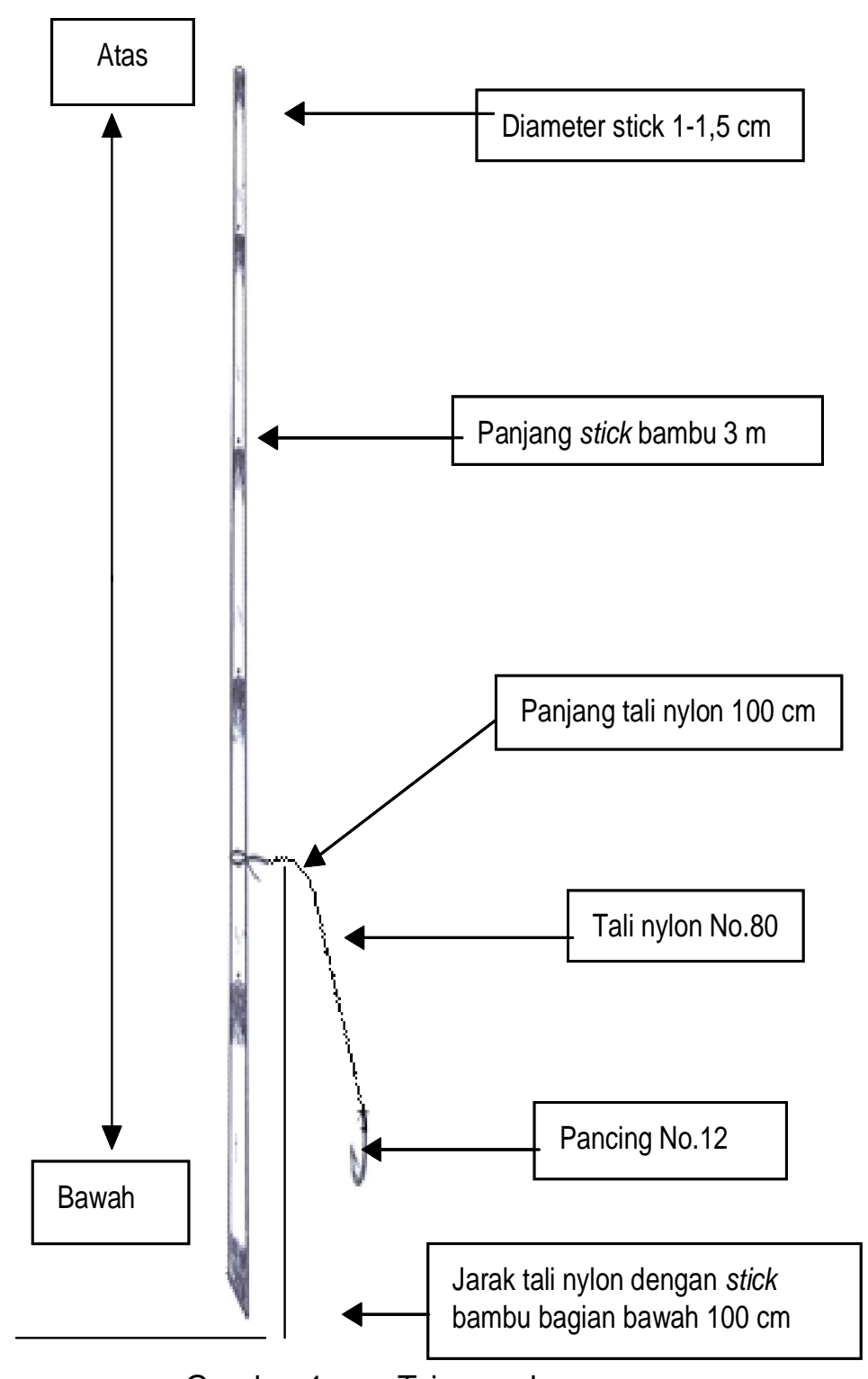

Gambar 1. Tajur rendam.

5. Setelah selesai pemasangan tajur rendam, maka dilakukan pengecekkan mulai dari tajur rendam yang pertama kali dipasang.

6. Tanda-tanda ikan tilan telah tertangkap, yaitu akan terlihat tajur rendam bergerak-gerak dan bila dipegang akan terasa bergetar.

7. Ikan tilan yang tertangkap tajur rendam diangkat secara pelan-pelan lalu dimasukkan di dalam perahu.

8. Agar ikan tilan tidak cepat mati, maka ditampung di dalam perahu motor diberi air sampai dengan kedalaman $\pm 20 \mathrm{~cm}$.

9. Ikan tilan yang tertangkap tajur rendam dilepaskan dengan cara memotong atau menggunting tali nylon didekat mulut ikan dengan menggunakan pisau atau gunting.

10. Setelah air sungai surut \pm 2 jam dari saat pasang tertinggi, maka semua alat tangkap tajur rendam dikemas dimasukkan di dalam perahu motor dan kegiatan penangkapan ikan tilan diakhiri sampai dengan di sini.

\section{HASIL DAN BAHASAN}

\section{Hasil Tangkapan}

1. Hasil pengamatan di lapangan ikan tilan (Mastacembelus spp.) dengan memakai alat tangkap tajur rendam 300 sampai dengan 400 buah dapat memberikan hasil berkisar 3 sampai dengan $15 \mathrm{~kg}$ per hari dan hasil rata-rata $8 \mathrm{~kg}$ per hari.

2. Ikan tilan yang tertangkap berukuran panjang 20 sampai dengan $50 \mathrm{~cm}$ per ekor dan panjang ratarata $30 \mathrm{~cm}$, bobot ikan berkisar 100 sampai dengan $1.500 \mathrm{~g}$ per ekor dan bobot ikan rata-rata $300 \mathrm{~g}$ per ekor (Gambar 3). 


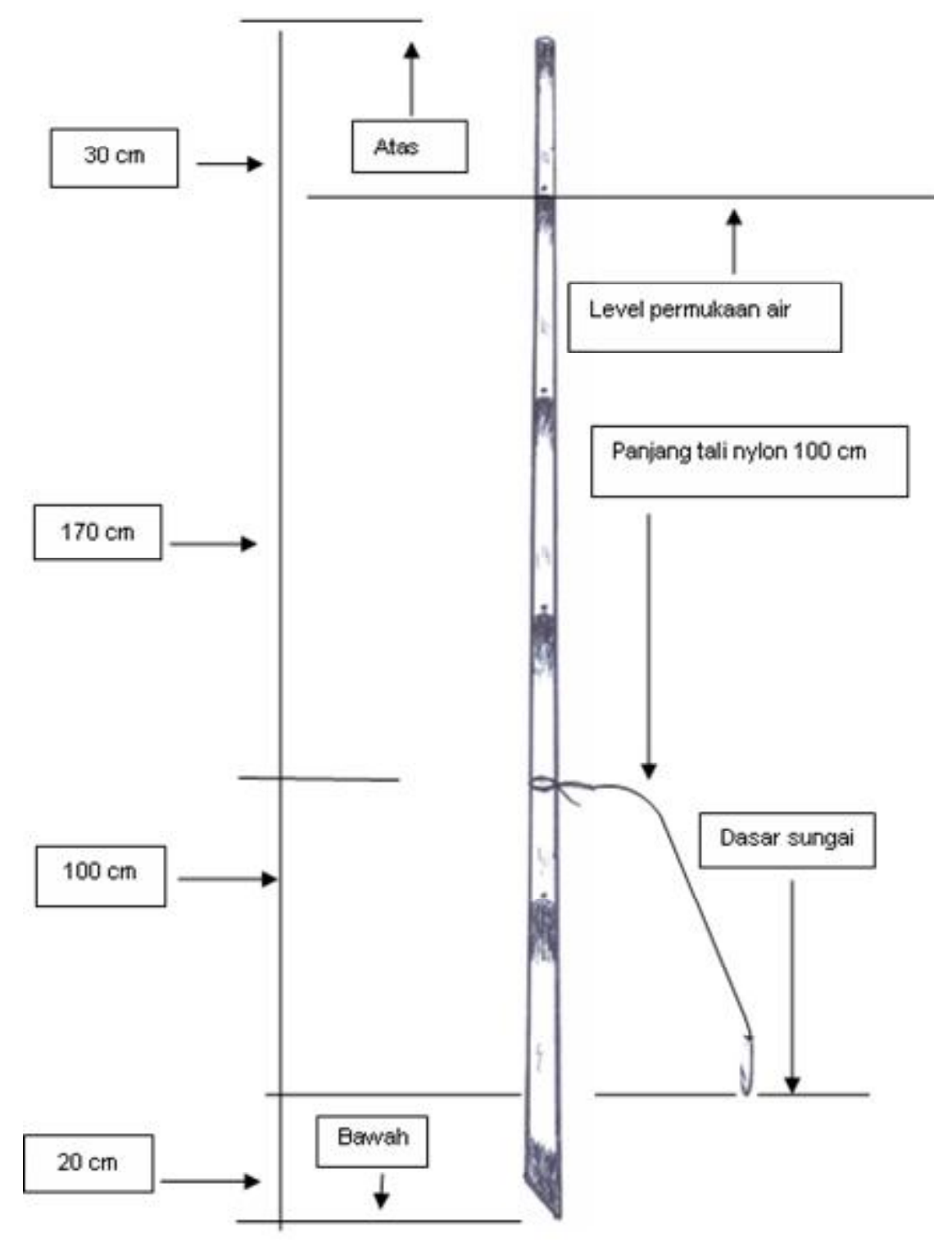

Gambar 2. Teknis pemasangan tajur rendam.

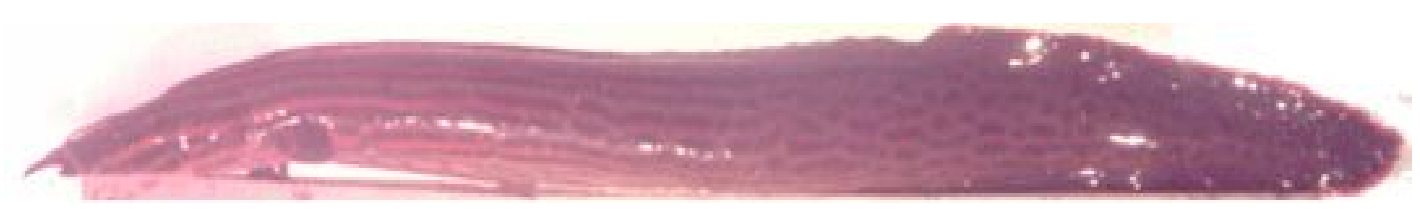

Gambar 3. Ikan tilan (Mastacembelus spp.) hasil tangkapan.

\section{KESIMPULAN}

Tajur rendam adalah alat tangkap tradisional yang banyak digunakan oleh nelayan di Sungai Musi bagian hilir khusus untuk menangkap ikan tilan (Mastacembelus spp.), juga merupakan alat tangkap yang selektif dan efektif untuk menangkap ikan tilan di Sungai Musi bagian Hilir, Sumatera Selatan.

\section{DAFTAR PUSTAKA}

Gaffar, A. K. 1997. Perikanan perairan umum di daerah aliran Sungai Musi, Sumatera Selatan. Makalah Simposium Perikanan Indonesia II Ujung Pandang. 2-3 Desember 1997. 1-13 hal.

Samuel \& S. Adjie 1996. Beberapa aspek limno biologi dan penangkapan di daerah aliran Sungai Musi bagian tengah, hulu, Sumatera Selatan. Prosiding Seminar Pengkomunikasian Hasil Penelitian 
Perikanan Perairan Umum di Sumatera Selatan. Lolitkanwar Palembang Badan Penelitian dan Pengembangan Pertanian. Departemen Pertanian. No.2 hal 43-52.

Samuel, Susilo A., \& Subagja. 2004. Inventarisasi dan distribusi biota serta karakteristik habitat perairan Sungai Musi. Prosiding Hasil-Hasil Riset. Pusat Riset Perikanan Tangkap. Badan Riset Kelautan dan Perikanan. Departemen Kelautan dan Perikanan. Hal.89-100.
Kottelat, M., Anthony J. Whitten, S. N. Kartikasari, \& S. Wirjoatmodjo. 1993. Freshwater fishes of western Indonesia and Sulawesi. Periplus edition and EMDI project. Indonesia. Jakarta. 232-233 PI.

\section{UCAPAN TERIMA KASIH}

Pada kesempatan ini penulis mengucapkan terima kasih sebesar-besarnya pada Bapak Jema'at sebagai narasumber. 